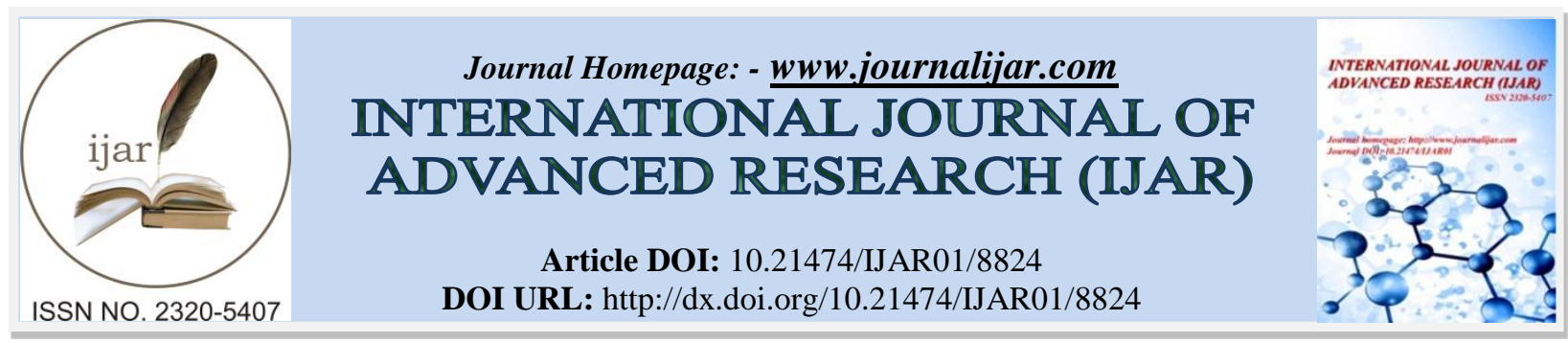

RESEARCH ARTICLE

\title{
ASSESSING THE RELATIONSHIP BETWEEN ATTITUDE AND AWARENESS REGARDING HIV/AIDS USING CANONICAL CORRELATION ANALYSIS.
}

Bushra Shamshad and Maria Ejaz.

Department of Statistics, University of Karachi, Pakistan.

\section{Manuscript Info}

Manuscript History

Received: 05 February 2019

Final Accepted: 07 March 2019

Published: April 2019

Key words:-

HIV/AIDS, Awareness,

Attitude/Behavior, Descriptive Statistics,

Canonical Correlation Analysis,

Canonical Correlation, Canonical

Variables.

\begin{abstract}
The objective of this study is to explore the relation between awareness regarding HIV/AIDS transmission and attitude towards the infected person using canonical correlation analysis. A survey was conducted in Karachi to accomplish the given objective. Initial analysis reveals that all though respondents were aware of mode of transfer of HIV/AIDS but still they have some misconceptions. Two canonical correlation has been retrieved as asymptotic statistical significance test for canonical correlation (approx. F for Wilks $\Lambda$ ) is significant only for two canonical correlation. Results show that students have sufficient knowledge regarding the HIV/AIDS transmission and this awareness leads participants to have sympathetic feelings for infected person.
\end{abstract}

Copy Right, IJAR, 2019,. All rights reserved.

\section{Introduction:-}

HIV - human immunodeficiency virus is a virus that causes AIDS-Acquired immunodeficiency syndrome. It is the virus once affected any human body; it will live in that till death of that human. A human body cannot get rid of HIV even with treatment.

HIV attacks on human immune system; especially CD4/T cells (infections fighting immune system cells). Once HIV attacks to a human body it reduces CD4/T cells, as immune system becomes weak and human body easily gets other infections or infection-related diseases. Time after time HIV destroys the number of CD4/T cells and the person can't fight off infections and diseases.

The weak immune system indicates the person has AIDS, which is last stage of HIV infection. HIV is transmitted through the exchange of body fluids from infected individuals such as blood, breast milk, semen and vaginal secretions. These are enduring myths that HIV can be transmitted through shaking hands, hugging, kissing, sharing personal objects, food or water, coughing/sneezing, sweat, sharing clothes, and insects' bites (HIVgov(2019)). Inadequate knowledge can leads to misperception of disease among people.

First case of HIV was found 39 years ago in west-central Africa (Sepkowitz (2001)). HIV is the world's most serious health problem. It is reported that 1.9 million People died from AIDS in 2004, 1.4 million in 2010 and 940,000 in 2017 (HIVgov(2019)). Among all over the world African Region is the most affected region, where 25.7 million people were living with HIV in 2017 and it is also two thirds of the global total of new HIV infections (WHO (2019)). First HIV case in Pakistan was noticed in Karachi in the year 1988 and it was caused due to blood transfusion (Vermund et al. (2006)). In 2017, UNAIDS has reported that in Pakistan, HIV estimates for adults and children are 150,000 (130,000 - 170,000), while adults, women, men aged 15 and over living with HIV are 
$140,000(130,000$ - 160,000), 43,000(38,000 - 49,000), 99000(87,000 - 110,00) respectively whereas children aged 0 to 14 living with HIV is $3500(3000-4000)$. HIV prevalence rate for adult aged 15 to 49 is $0.1(0.1-0.1)$, whereas HIV prevalence rate for women and men aged 15 to 49 are $<0.1(<0.1-<0.1)$ and $0.2(0.1-0.2)$ respectively (HIVgov (2019)).

Currently no effective cure /medicine are discovered for HIV but it can be controlled with proper medical care. Antiretroviral therapy or ART is used to treat HIV. Proper usage of this medicine keeps the HIV infected person healthy, and reduces risk of infections. In 1990s when ART was not introduced HIV used to cause AIDS in few years while now a days HIV diagnosed patients when treated with ART live healthy and active till as long as an healthy person.

\section{Literature Review:-}

HIV/AIDS is major worldwide health issue. Outbreak of HIV/AIDS is increasing every day globally. According to UNAIDS in 2017, AIDS cause about Less than 1 million deaths every year and 39.7 million people were living with this infection globally. As HIV/AIDS is worldwide problem therefore, many studies in different region have been conducted.

Choudhary et al. (2015), conducted study among undergraduate students in Irish university and showed that students had adequate knowledge of HIV/AIDS but had misconception regarding AIDS transmission through mosquito bite. Same result was found in Inungu et al. (2009) research which was conducted in Midwestern University, United States. Choudhary et al. (2015) study also revealed sympathetic behavior of students towards the infected. Asante and Oti-Boadi (2013) conducted study in Ghana, South Africa, and revealed that although students were aware of HIV/AIDS transmission but could not indicate that HIV is the main cause of AIDS. He also found the significant difference in HIV/AIDS knowledge between genders, as female had more knowledge than male. Which were consistent with Aluede et al. (2005) findings, that was carried out in Nigerian university for undergraduate students, they proved that male and female differ in knowledge regarding AIDS given that they had adequate knowledge but their findings revealed that male are more knowledgeable than females. These two studies are inconsistent with Choudhary et al. (2015) and Huang et al. (2005), as their researches proved no significant difference between gender knowledge.

Ahmed et al. (2016) conducted research in Pakistan through online survey to find out the level of awareness among Pakistanis. This study revealed that majority of Pakistanis are aware of HIV infection but they have not screened for HIV, because they believe that the main reason of HIV/AIDS transmission are pre/extra marital and homosexuality, and in Islam these practices are impermissible. Therefore, Pakistan being Islamic country has less chance to develop this disease.

Research of Khan et al. (2008) at Peshawar, Pakistan, showed the satisfactory knowledge among the medical students. He found the non-medical students lack in awareness therefore he suggested that HIV awareness should be the part of our education programs for both medical and non-medical students. Mustafa et al. (2018) conducted research in four different educational institutes at Lahore, Pakistan and showed the same results that elder age, female gender and medical students have higher knowledge regarding the AIDS/HIV.

Farid-ul-Hasnain et al. (2013) used a qualitative research through focus group to find the cultural practices for reproductive health and awareness and knowledge regarding HIV/AIDS in Karachi, Pakistan. This research showed that uneducated people have less knowledge than educated regarding HIV prevention. Lack of HIV/AIDS knowledge was found among youth as well.

Raza et al. (1998) conducted study in Lahore, Pakistan. This research revealed the knowledge gap among females than males and showed that most of the participants had misconception regarding AIDS transmission through causal conduct. This research also revealed the insensitive attitude towards infected as majority of participants were agreed to isolate the infected person. Huang et al. (2005) findings support the above study; it was conducted among undergraduate students in China. His findings also showed misconception regarding AIDS transmission. Students in this study perceived that AIDS can be transmitted by casual contact and needle sharing does not cause HIV/AIDS transmission. Research of Odu et al. (2008) is inconsistent with Raza et al. (1998) as this research found that majority of respondents were aware of HIV/AIDS transmission and also had sympathetic behavior towards the infected. 


\section{Discussion:-}

The study was conducted to evaluate the knowledge among students from various universities in Karachi accruing degrees in various fields like, pharmacy, dentistry, chemistry, physiology, psychology, engineering, clinical pathology, medicine, computer science, finance, statistics etc., regarding a viral disease HIV/AIDS. Conventional sampling was done to collect the data. Through a questionnaire consist of 20 questions. In a sample of 257 respondents, $68 \%$ females and $32 \%$ males were participated. The respondent's age mostly varies from 16-29 years, having few outside this range. Among them only $13 \%$ claim that they can recognize the person having HIV by their physical appearance. Whereas, almost 51\% cannot recognize the person. The study showed that the students have partial understanding regarding HIV/AIDS transmission as although a reasonable proportion of students are able to identify main cause of HIV/AIDS transmission but have misconceptions too of correctly identifying the causes.

Table 1: Descriptive Statistics for Positive (Yes) Response for all variables, all values are in percentages.

\begin{tabular}{|c|c|c|c|}
\hline Variables & Female & Male & Overall \\
\hline AIDS is severe phase of HIV & 63.9 & 39.8 & 56.3 \\
\hline HIV/AIDS is contagious & 53.9 & 55.4 & 54.4 \\
\hline HIV/AIDS cause by sexual interaction & 91.7 & 97.6 & 93.5 \\
\hline Cause by blood transfusion & 92.2 & 91.6 & 92 \\
\hline Cause by mother to unborn & 67.2 & 44.6 & 60.1 \\
\hline Cause by sharing sharp objects & 89.4 & 84.3 & 87.8 \\
\hline Cause by sharing toilets & 27.2 & 19.3 & 24.7 \\
\hline Cause by utensils & 32.8 & 33.7 & 33.1 \\
\hline Cause by sharing clothes & 31.1 & 19.3 & 27.4 \\
\hline Spread by sneezing/coughing & 39.4 & 27.7 & 35.7 \\
\hline Cause by shaking hands & 14.4 & 10.8 & 13.3 \\
\hline Spread by mosquito bites & 21.7 & 27.7 & 23.6 \\
\hline Spread by sharing swimming pools & 27.2 & 16.9 & 24 \\
\hline Cause by black magic & 12.8 & 7.2 & 11 \\
\hline HIV/AIDS Curable disease & 18.3 & 22.9 & 19.8 \\
\hline Spending some time with infected & 56.1 & 57.8 & 56.7 \\
\hline Infected person bears bad character & 15.6 & 22.9 & 17.9 \\
\hline Infected feel ashamed & 12.2 & 15.7 & 13.3 \\
\hline Infected indulge in immoral practices & 18.9 & 15.7 & 17.9 \\
\hline Infected deserve good job & 51.7 & 48.2 & 50.6 \\
\hline Infected should be marginalized & 22.2 & 26.5 & 23.6 \\
\hline
\end{tabular}

Our findings reflects that $54.4 \%$ students know that HIV is contagious disease and this finding is inconsistent with the survey carried out by Khan et al. (2008), as $94.6 \%$ students in their studies think that HIV is a communicable disease. The main reason of the inconsistent result between both studies could be that they collected data from medical students and it is obvious medical students have more knowledge regarding HIV disease as compared to nonmedical students. In our survey 56.6\% students are in favor of spending time with infected person and this result is consistent with Shaikh et al. (2007) findings and MICS survey (2014) conducted in Sindh which included only female, as $60 \%$ medical students and $83.4 \%$ housewives think that HIV infected person deserve their time respectively. This result is also similar to the study conducted by Ali \& Ahmed (2015) as 58.3\% participants have positive attitude towards infected person. The similar positive results regarding attitude indicates that our society has compassionate feelings and accepting behavior towards HIV infected person regardless of their qualification/ education level, but Zafar et al. (2014) studied showed that 75.8\% fishermen has negative attitude towards infected persons.

In our survey, $32.8 \%$ female believe that sharing utensils can cause HIV and this finding is similar with the study Raza et al. (1998) as $28 \%$ female in their survey think that sharing utensils might lead to HIV. On the other hand, the percentage is almost half in our findings as 59\% male in their survey think that sharing utensil can cause HIV while in our survey only $33.7 \%$ agree.

Our findings reflect that $21.7 \%$ female think that mosquito bite can cause HIV and $12.2 \%$ female believe that supernatural means can cause HIV/AIDS these findings are inconsistent with the MICS survey (2014) as 78.8\% 
agree that HIV can be transmitted through mosquito bite and $71.8 \%$ agree that supernatural means can be the reason of HIV/AIDS. The reason of this huge difference in percentage can be attributed to the lack of awareness regarding HIV transmission especially in rural areas of Sindh as MICS survey was collected from both urban and rural areas. The result in this study shows that $92 \%$ and $93.5 \%$ students believe that HIV can be transmitted through blood donation and sexual interaction respectively. The findings of these two modes of transmissions are consistent with the other studies which were conducted in Pakistan. These similar results indicate that youth is partially aware of the real cause of HIV transmission.

In our findings, $56.3 \%$ students know that AIDS is the severe phase of HIV and these results are inconsistent with Khan et al. (2008) as 79\% students have better knowledge regarding HIV because the respondent in our study are from diverse field as compared to one that belonged to medical field. $60.1 \%$ students attribute the transmission of HIV from mother to unborn child, it is inconsistent with the findings of [8] as in this study, 95.7\% students believe that HIV can be transmitted from mother to unborn child. $10.8 \%$ male and $14.4 \%$ female in our survey think that HIV can be transmitted by shaking hands and these results are much better than the survey conducted by Raza et al. (1998) in which $68.49 \%$ male and $59.972 \%$ believed that HIV can cause by shaking hands which means students in our survey have better understanding that HIV cannot be transmitted through handshaking. The result in survey reflects that $35.7 \%$ students think that HIV can be transmitted through coughing and sneezing and these result are inconsistent with the findings of Choudhary et al. (2015) as in his survey only $5.2 \%$ students believe that HIV can be transmitted through this mode. Whereas our findings depict that $89.4 \%$ students think that transmission of HIV through sharp object is possible and these results are consistent with findings of MICS survey (2014) conducted in Sindh but inconsistent with Abrar \& Ghouri (2010) as it showed 48.8\% .

\section{Method:-}

Canonical Correlation Analysis is multivariate technique that is used to quantify the association between two sets of variables. In CCA parameters are estimated for two different sets of variables called predictor or dependent sets of variable and criterion or independent sets of variables. Then these parameters are used to find the linear combination between the original grouped variables like simple linear regression. These linear combinations are called canonical variables or variates. The correlation between these canonical variates are called canonical correlation (CC). Parameters are estimated in such a way that the correlation between the first canonical variate should be maximum among all pairs of canonical variates. The algorithm of canonical correlation generates a canonical variables in such a way that they are correlated with each other but orthogonal to the other canonical variates. The number of canonical correlation are equal to the smaller number of variables in both set (dependent and independent sets) (Johnson \& Wichern (2007)).

The canonical variates for the linear combination can be expressed as, Canonical variates for predictor variables set

$$
\begin{aligned}
& \lambda_{1}=\Pi_{11} P_{1}+\Pi_{12} P_{2}+\ldots \ldots \Pi_{1 q} P_{q} \\
& \cdot \\
& \cdot \\
& \bar{\lambda}_{j}=\Pi_{j 1} P_{1}+\Pi_{j 2} P_{2}+\ldots . . \Pi_{j q} P_{q}
\end{aligned}
$$

Canonical variates for criterion variables set

$$
\begin{aligned}
& \hbar_{1}=\Psi_{11} C_{1}+\Psi_{12} C_{2}+\ldots . \Psi_{1 p} C_{p} \\
& \cdot \\
& \cdot \\
& \hbar_{i}=\Psi_{i 1} C_{1}+\Psi_{i 2} C_{2}+\ldots . \Psi_{i p} C_{p}
\end{aligned}
$$


Where,

$\Pi_{11}, \Pi_{21}, \ldots ., \Pi_{j 1}$ are the weights for dependent set of variables
$\Psi_{11}, \Psi_{21}, \ldots \ldots ., \Psi_{i 1}$ are the weights for independent set of variables

$C_{p}$ are the criterion variables

$P_{q}$ are the predictor variables

$\mathrm{p}$ is number of criterion variables

$\mathrm{q}$ is number of predictor variables

The properties of canonical variates are as follows

$$
\begin{aligned}
& v\left(\hbar_{i}\right)=v\left(\lambda_{j}\right)=1 \\
& \operatorname{cov}\left(\lambda_{i}, \lambda_{u}\right)=\operatorname{cov}\left(\lambda_{u}, \lambda_{i}\right)=0, u \neq i \\
& \operatorname{cov}\left(\hbar_{i}, \hbar_{u}\right)=\operatorname{cov}\left(\hbar_{u}, \hbar_{i}\right)=0, u \neq i \\
& \operatorname{cov}\left(\lambda_{i}, \hbar_{u}\right)=\operatorname{cov}\left(\lambda_{u}, \hbar_{i}\right)=0, u \neq i
\end{aligned}
$$

Many multivariate test are available in different software for the significant of canonical correlation. Many criteria are used to test the relation between independent and dependent set of variables, which includes Wilks' lambda, Lawley-Hotelling statistics, Pillai's test, and Roy's. F- Approximation are calculated for all above four statistics to test the significance of canonical correlation (Hair et al. (2005); Rencher (2002). Cross loadings and loadings/ canonical structure correlation are considered important for interpreting canonical correlation (Sherry \& Henson (2015)). Canonical loadings are the correlation between original variable and canonical variate. Whereas, cross loadings are the correlation between original dependent variable and independent canonical variate, vice versa is also true for above cases. Those variables are considered significant whose loadings are greater than 0.3 as it indicated that original variable shared $9 \%$ of variance with canonical variate (Lambert \& Durand (1975)).

\section{Results:-}

The missing values in the data set are replaced by using a multivariate imputation by chained equations (mice) package (Buuren et. al (2019)) in R software. The package include following four different methods to impute missing values. 1) Linear regression for continuous data 2) logistic regression for categorical data with two levels 3 ) Bayesian polytomous regression for categorical data with two or more levels and 4) proportional odds model for ordered categorical data. This package first, impute the missing values $\mathrm{n}$ times and then pool the results of $\mathrm{n}$ completed data sets. Then it stores the imputed values. Once the missing values are replaced we applied the canonical correlation technique to find the relationship between awareness about HIV in the society (independent set of variables) against behavior of individuals towards the infected persons (dependent set of variables).

The Cronbach's for 32 items in the survey give a value 0.583 in order to test the reliability of the survey. The value increases from 0.583 to 0.641 after deleting age variable. Table 2 shows the significance test for entire model. All $\mathrm{p}$ values are less than 0.05 which rejects Ho and indicates that there is a relationship between two sets of variables.

Table 3 shows the canonical correlation for canonical variates. Table 3 displays that first canonical correlation can explain $17.41 \%$ of variation in dependent set of variables due to independent set of variables, and second canonical correlation can explain $11.13 \%$ of variation in dependent sets by independent variable sets.

Table 2: Statistical Significance Test for Overall Model

\begin{tabular}{|l|l|l|l|l|l|}
\hline Test Name & Value & Approx. F & Hypothesis DF & Error DF & P-value \\
\hline Pillai & 0.7728 & 1.76069 & 120 & 1976.0000 & $<0.001$ \\
\hline Hotelling & 0.9306 & 1.84768 & 120 & 1906.0000 & $<0.001$ \\
\hline Wilks & 0.4292 & 1.80929 & 120 & 1720.9300 & $<0.001$ \\
\hline Roy & 0.2410 & & & & \\
\hline
\end{tabular}


Table 3: Canonical Correlations for all Canonical Functions

\begin{tabular}{|l|l|l|}
\hline Canonical correlation & $\mathrm{R}_{\mathrm{c}}^{2}$ & $\mathrm{R}_{\mathrm{c}}^{2}(\%)$ \\
\hline 0.417 & 0.174 & 17.41 \\
\hline 0.334 & 0.111 & 11.13 \\
\hline 0.259 & 0.067 & 6.70 \\
\hline 0.195 & 0.038 & 3.81 \\
\hline 0.164 & 0.027 & 2.67 \\
\hline 0.099 & 0.010 & 0.98 \\
\hline
\end{tabular}

Table 4: Statistical Significance Test for Canonical Correlation

\begin{tabular}{|l|l|l|l|l|l|}
\hline Roots & Wilks lambda & Approx. F & Hypothesis DF & Error DF & P-value \\
\hline 1 to 6 & 0.596 & 2.033 & 66 & 1321.765 & $<0.001$ \\
\hline 2 to 6 & 0.730 & 1.611 & 50 & 1129.858 & 0.0050 \\
\hline 3 to 6 & 0.849 & 1.153 & 36 & 931.1081 & 0.2490 \\
\hline 4 to 6 & 0.929 & 0.771 & 24 & 722.777 & 0.7758 \\
\hline 5 to 6 & 0.985 & 0.272 & 14 & 500 & 0.9964 \\
\hline 6 to 6 & 0.996 & 0.171 & 6 & 251 & 0.9843 \\
\hline
\end{tabular}

Table 4 depicts the significance test for canonical correlation. It has been proposed that number of canonical correlations are equal to the smaller number of variables in both set (dependent and independent sets), therefore only 6 functions are derived. Only first two canonical correlation are significant (i.e. p-value $<0.05$ ), therefore only two canonical correlations will be retrieved for further analysis.

Table 5 shows the structural loadings regarding HIV/AIDS awareness and behavior towards infected person. This table reflects that the most important variables for the prediction of behavior towards infected person in first canonical variates are

Table 5: Loadings and Canonical Variate Adequacy for First and Second Canonical Function

\begin{tabular}{|c|c|c|c|c|}
\hline Variables & CV1 & $\begin{array}{l}\text { CV1 } \\
\text { Adequacies }\end{array}$ & $\mathrm{CV} 2$ & $\begin{array}{l}\text { CV2 } \\
\text { Adequacies }\end{array}$ \\
\hline \multicolumn{5}{|l|}{ Independent Set } \\
\hline HIV/AIDS cause by sexual interaction & -0.158 & \multirow{11}{*}{0.1249} & -0.552 & \multirow{11}{*}{0.077} \\
\hline Cause by blood transfusion & -0.510 & & -0.049 & \\
\hline Cause by mother to unborn & -0.600 & & -0.046 & \\
\hline Cause by sharing sharp objects & -0.294 & & -0.309 & \\
\hline Cause by sharing toilets & 0.277 & & 0.490 & \\
\hline Cause by utensils & 0.162 & & 0.220 & \\
\hline Spread by sneezing/coughing & 0.299 & & 0.229 & \\
\hline Cause by shaking hands & 0.240 & & -0.180 & \\
\hline Spread by mosquito bites & 0.037 & & -0.008 & \\
\hline Spread by sharing swimming pools & 0.132 & & 0.189 & \\
\hline Cause by black magic & 0.612 & & -0.196 & \\
\hline \multicolumn{5}{|l|}{ Dependent set } \\
\hline $\begin{array}{l}\text { Psychological issues due to societal behaviour towards } \\
\text { infected person }\end{array}$ & -0.540 & \multirow{6}{*}{0.329} & -0.304 & \multirow{6}{*}{0.1174} \\
\hline Infected person bears bad character & 0.422 & & 0.074 & \\
\hline Infected feel ashamed & 0.856 & & -0.126 & \\
\hline Infected indulge in immoral practices & 0.773 & & 0.173 & \\
\hline Infected deserve good job & 0.009 & & -0.567 & \\
\hline Infected should be marginalized & 0.417 & & 0.489 & \\
\hline
\end{tabular}

Transmission of AIDS through black magic (supernatural means) (with loading 0.612)

Transmission of AIDS by mother to unborn child (with loading -0.600)

Transmission of AIDS by blood transfusion (with loadings -0.510) 
Spread of AIDS by sneezing/coughing (with loading 0.299)

Transmission of AIDS by sharing sharp objects (with loadings -0.294)

Transmission of AIDS through toilet sharing (with loading 0.277)

The above loadings show students perceive that main modes of AIDS transmission are mother to unborn child, blood transfusion and sharing of sharp objects. Whereas, students believe that AIDS can't be transmitted through supernatural means, sneezing/coughing and toilet sharing.

Loadings of first canonical variate for behavior towards the infected shows that contribution of all variables are high for first canonical variable except infected deserve good job. Psychological issues due to societal behavior is positively correlated with main modes of AIDS transmission. This shows that those who are aware of main channels of AIDS transmission believes that societal behavior leads the infected person towards suicidal thoughts and other psychological issues. It is also captivating that all behavioral variables except psychological issues due to societal behavior are positively correlated with misconceived modes of AIDS transmission. This reflects that as the chances of misconception regarding the AIDS transmission increases the behavior towards infected becomes insensitive.

From the first canonical correlation function it can be concluded that correct awareness regarding the HIV/AIDS leads the sympathetic feelings for infected person. First canonical function represents the approximately $12 \%$ variance of the original variables for independent set of variables and 32.9\% variance for dependent set of variables. The most important variables for the prediction of behavior towards infected person in second canonical variates, are transmission of AIDS by sexual interaction (with loading -0.552), transmission of AIDS by sharing toilets (with loading 0.490), and transmission of AIDS by sharing sharp objects (with loading -0.309). Loadings of behavioral variable demonstrate that infected deserves good job (with loading -0.567), infected should be marginalized (with loading 0.489), and psychological issues due to societal behavior (with loading -0.304) are the variables that contributes for second canonical correlation. It can be observed that infected deserves good job and psychological issues due to societal behavior are positively correlated with correct mode of HIV/AIDS transmission. This depicts that adequate knowledge regarding HIV/AIDS transmission leads to sympathetic behavior and also leads to assume that societal behavior can compel infected to commit suicide or cause any other psychological disorder. Some misconceptions can also be observed in second canonical correlation and hence this leads to insensitive behavior towards the infected person. Second canonical function also shows awareness regarding HIV/AIDS of participants leads to positive behavior towards the infected person. Second canonical variate for independent sets represents the approximately $7 \%$ variance of the original variables, and for dependent sets it approximately explains $11.74 \%$ variance of original variables.

From both canonical variates it can be concluded that adequate awareness regarding HIV/AIDS of participants leads to positive behavior towards the infected person.
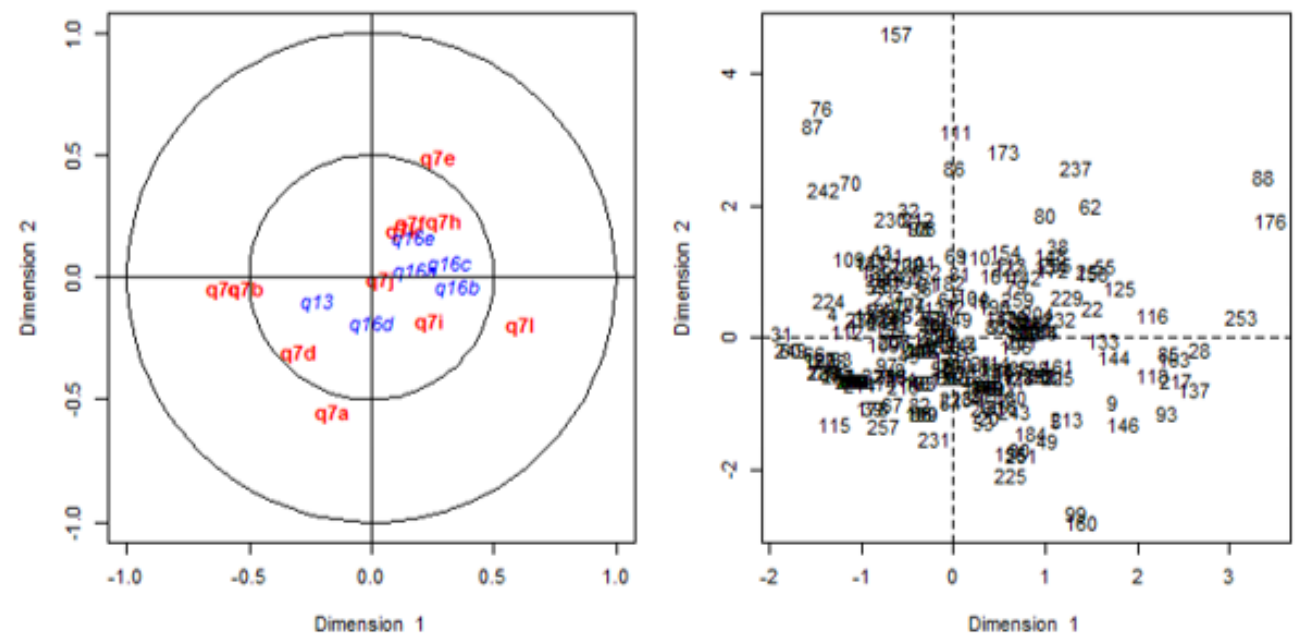

Figure 1: Biplot of two canonical functions 
Table 6: Labels Assigned to Variables for Figure 1

\begin{tabular}{lc}
\hline \hline \multicolumn{1}{c}{ Questions } & Labels \\
\hline HIV/AIDS cause by sexual interaction & q7a \\
Cause by blood transfusion & q7b \\
Cause by mother to unborn & q7c \\
Cause by sharing sharp objects & q7d \\
Cause by sharing toilets & q7e \\
Cause by utensils & q7f \\
Spread by sneezing/coughing & q7h \\
Cause by shaking hands & q7i \\
Spread by mosquito bites & q7j \\
Spread by sharing swimming pools & q7k \\
Cause by black magic & q7l \\
Psychological issues due to societal behaviour towards & q13 \\
infected person & q16a \\
Infected person bears bad character & q16b \\
Infected feel ashamed & q16c \\
Infected indulge in immoral practices & q16d \\
Infected deserve good job & q16e \\
Infected should be marginalized &
\end{tabular}

In Fig 1, graph (a) shows the representation of variables on two sets of canonical function and graph (b) shows representation of individual participant on two sets of canonical function.

It can be observed from graph (a) that all variables of behavior towards HIV/AIDS infected person have impact on both canonical functions within circle of radius 0.5. Infected deserves good job (q16d) has significant influence on second canonical function. Whereas, infected bears a bad character (q16a) has significant impact on first canonical function.

Among the variables of HIV/AIDS awareness, transmission of AIDS by blood transfusion (q7b) and through mother to unborn child (q7c) have significant impact on first canonical function. Transmission of AIDS through sharing toilets (q7e) and through sexual interaction (q7a) have greater impact on second canonical function.

Transmission of AIDS through mosquito bites (q7j) has no impact on either of canonical function. Transmission of AIDS through sharing sharp objects (q7d) has almost same impact on both canonical functions.

Graph (b) reveals observation 88 and 176 as outliers for first canonical function and 76, 99157 and 160 outliers for second canonical function. Participants 76, 88, 99, 157, 160, 176, have misconception about the transmission of AIDS and have also insensitive attitude towards the infected. On the other hand, participant 76 has less knowledge about transmission of HIV/AIDS and have provided neutral response to most of the questions. This conclude that insufficient awareness regarding AIDS leads insensitive behavior towards infected. Canonical correlation function results also verify that adequate knowledge regarding AIDS transmission leads to sympathetic behavior. Graph 2 does not display any group, structure, trend and cluster of observations.

\section{Conclusion:-}

This research shows that students have adequate knowledge regarding the HIV/AIDS transmission as percentages for correct mode of transmission are sufficiently high but students also have some misconceptions regarding the mode of HIV/AIDS transmission. It has been observed that $39 \%$ students believe AIDS can be transmitted by sneezing and coughing. This is the highest percentage among all misconceived variables for HIV/AIDS transmission. It is proved from canonical correlation analysis that adequate knowledge regarding HIV/AIDS leads sympathetic attitude towards the infected. As students have false conception regarding the HIV/AIDS transmission, 
therefore it is recommended either to conduct workshops on the awareness of HIV/AIDS transmission or incorporate some modules related to HIV/AIDS awareness in educational programs.

\section{Acknowledgement:-}

We would like to thank Afshan Zehra, Ramsha Akhlaq, Komal Rafiq, Shamama Mobin and Aiman Fazal for their support in this research in all stages. We highly appritaite their struggle in conducting the survey. We would also like to thank Prof. Dr. Junaid Saghir Siddiqi for his valuable suggestions and time.

\section{References:-}

1. Abrar, N. \& Ghouri, A. M. (2010), "AIDS/ HIV Knowledge, Attitude and Beliefs of Adolescents of Pakistan," European Journal of Social Sciences, vol. 16, no. 2, pp. 267-277.

2. Ahmad, A., Ashraf, S., Fatima, A., Shah, A., Saleem, S., \& Yasmeen, S. A. (2016). HIV Awareness in Pakistan: A Survey-Based Study. Journal of Coastal Life Medicine, vol. 4, no. 6, pp. 496-499.

3. Ali, M. G. \& Ahmad, M. O. (2015). Knowledge, Attitude and Practices Regarding HIV/AIDS among the community of Rawalpindi and Islamabad, Pakistan. International Journal of Research in Medical Sciences, vol. 3, no.11, pp. 3080-3083.

4. Aluede, O., Imhonde, H. O., Maliki, A. E. \& Alutu, A. N.G. (2005). Assessing Nigerian University Students' Knowledge about HIV/AIDS. Journal of Social Sciences, vol. 11, no. 3.

5. Asante, K. O., Oti-Boadi, M. (2013) "HIV/AIDS Knowledge among Undergraduate University Students: Implications for Health Education Programs in Ghana," African Health Sciences, vol. 13, no. 2, pp. 270 - 277.

6. Choudhary, H. A., Ali, R. A. \& Altaf, S. (2015), "Knowledge, Behavior and Attitudes Regarding HIV/AIDS among Undergraduate Students in an Irish University," International Journal of Surgery and Medicine, vol. 1, no. 2, pp. 58-66.

7. Farid-ul-Hasnain, S., Johansson, E., Gulzar S. \& Krantz, G. (2013). Need for Multilevel Strategies and Enhanced Acceptance of Contraceptive Use in Order to Combat the Spread of HIV/AIDS in a Muslim Society: A Qualitative Study of Young Adults in Urban Karachi, Pakistan. Global Journal of Health Science, vol. 5, no. 5, pp. 57-66.

8. H. Khan, M. Ishaq, H. Khan, T. Ishaq, "Knowledge and Attitude of Students Regarding HIV/AIDS in Peshawar University," Rawal Medical Journal, vol. 33, pp. 18-20, 2008.

9. Hair, J. F., Black, W. C., Babin, B. J., Anderson, R. E. (2005). Multivariate Data Analysis, Dorling Kindersley Pvt. Ltd, licensees of Pearson Education in South Asia, pp. 231-312.

10. HIVgov, "About HIV\&AIDS," https://www.hiv.gov/hiv-basics/overview/about-hiv-and-aids/what-are-hiv-andaids. 2019.

11. HIVgov, "Global Statistics," https://www.hiv.gov/hiv-basics/overview/data-and-trends/global-statistics, 2019.

12. Huang, J., Bova, C., Fennie, K. P., Rogers, A. \& Williams, A. B. (2005) Knowledge, Attitudes, Behaviors, and Perceptions of Risk Related to HIV/AIDS among Chinese University Students in Hunan, China," AIDS Patient Care and STDs, vol. 19, no. 1.

13. Inungu, J., Mumford, V., Younis, M., \& Langford, S. (2009) "HIV Knowledge, Attitudes and Practices among College Students in the United States," Journal of Health and Human Services Administration, vol. 32, no. 3, pp. 259-277.

14. Johnson, R. A., \& Wichern, D. W. (2007) Applied Multivariate Statistical Analysis, Pearson Prentice Hall, pp. 539-574.

15. Lambert, Z. V. \& Durand, R. M. (1975). Some Precautions in Using Canonical Analysis. Journal of Marketing Research, vol. 12, pp. 468-475.

16. Mustafa, Z. U., Salman, M., Afridi, M. S. K., Asif, N., Shehzadi, N., \& Hussain, K. (2018) A Cross Sectional Assessment of Knowledge, Attitudes and Believes and Concerning HIV/AIDS among Pakistani Universities Population. Indian Journal of Pharmaceutical Sciences, vol. 80, no. 1, pp. 210-214.

17. Odu, O. O., Asekun-Olarinmoye, E. O., Bamidele, J. O., Egbewale, B. E., Amusan, O. A. \& Olowu, A. O. (2008). Knowledge, attitudes to HIV/AIDS and sexual behavior of students in a tertiary institution in southwestern Nigeria. The European Journal of Contraception and Reproductive Health Care, vol. 13, no. 1, pp. 9096.

18. Raza, M. I., Afifi, A., Choudhry, A. J., \& Khan, H. I. (1998). Knowledge, Attitude and Behavior towards AIDS among Educated Youth in Lahore, Pakistan. The journal of Pakistan Medical Association, vol. 48, no. 6, pp. 179-182.

19. Rencher, A. C. (2002). Methods of Multivariate Analysis. A Wiley-Interscience publication, pp. 367-369. 
20. Sepkowitz, K. A. (2001). AIDS â€” The First 20 Years. New England Journal of Medicine, 344(23), 17641772 .

21. Shaikh, F. D., Khan, S. A., Ross, M. W. \& Grimes, R. M. (2007) Knowledge and Attitudes of Pakistani Medical Students towards HIV-Positive and/or AIDS Patients. Psychology, Health \& Medicine, vol. 12, no. 1, pp. 7-17.

22. Sherry, A. \& Henson, R. K. (2015). Conducting and Interpreting Canonical Correlation Analysis in Personality Research: A User-Friendly Primer. Journal of Personality Assessment, vol. 84, no. 1, pp. 37-48.

23. Sindh Bureau of Statistics and UNICEF, Sindh Multiple Indicator Cluster Survey 2014, Final Report, Karachi, Pakistan, Sindh Bureau of Statistics and UNICEF, pp. 187-193, 2015.

24. UNAIDS Pakistan, http://www.unaids.org/en/regionscountries/countries/pakistan/. 2019.

25. Vermund, S. H., White, H., Shah, S. A., et al. (2006) "HIV/AIDS in Pakistan: Has the explosion begun?," Journal of Pakistan Medical Association, vol. 56, no. 1.

26. World Health Organization HIV/AIDS, https://www.who.int/news-room/fact-sheets/detail/hiv-aids. 2019.

27. Zafar, M., Nisar, N., Kadir, M., Fatmi, Z., Ahmed, Z. and Shafique, K. (2014). Knowledge, Attitude and Practices Regarding HIV/AIDS among Adult Fishermen in Coastal Areas of Karachi. BMC Public Health, vol. 14 , no. 437. 